\title{
Social Capital in Rural Ethiopia Agrarian Society
}

\author{
Alemayehu Derbe \\ Lecturer and Researcher, Department of Economics, PO box 21, Arba-Minch University, Ethiopia \\ $\mathrm{PhD}$ fellow, School of Agricultural Economics and Agri-Business Management, PO box 138, Dire Dawa, \\ Haramaya University, Ethiopia
}

\begin{abstract}
Social capital has been focus of many researchers in recent years. Development of communities is a continuous process in order to sustain communities through utilizing their assets in a world that is increasingly becoming unpredictable and difficult in terms of togetherness and caring concerns for sustainability and productivity. Social capital in agriculture was reviewed from rural community perspectives and seen as a motivating and attaching force for the agrarian societies that benefits the agriculture. This review tries to capture some of the existing social capital and their contribution in rural Ethiopia agrarian societies.
\end{abstract}

Keywords: Social capital, sustainability and agrarian societies

DOI: $10.7176 / \mathrm{DCS} / 9-6-03$

Publication date:June $30^{\text {th }} 2019$

\section{INTRODUCTION}

Development from the social perspective can be seen as a group's effort in making a continuous planned change to increase their wellbeing. Community development talks on all facets of human life. The traditional approach was more eradicating poverty and raising standards of living. Now there is a paradigm shift to address all facets of human life wrapping the concept in all approaches, either top-down or bottom-up dimensions changing various roles of people in the society. Social capital can be seen as the assets of the poor and their communities which they fall back to and help negotiate their way in an unpredictable and difficult world (Wong, 2007).

Ethiopian agriculture is characterized by low productivity which is associated with low input usage (such as improved seed varieties and fertilizer), significant post-harvest loss, population pressure, poor farming practices, and land degradation, among others. Besides measures that would take population pressure off agriculture, among others, potential remedies lie in the promotion of agricultural innovations to sustainably improve agricultural productivity whilst increasing the efficiency of smallholder agriculture.

Evidence from other countries, however, suggests that social networks play a central role in people's lives in so many ways including in shaping beliefs, preferences, and decisions (Jakson, 2011). There is, for example, evidence on the role of social networks on the diffusion of information, new products, and technologies (Jackson and Yariv, 2011); informal insurance and risk sharing (Fafchamps, 2011); and labor and credit networks for economic activities (Munshi, 2011) and in the situations of the low level of information on trade partners, GebreMadhin (2001) showed, Ethiopian grain traders could reduce the transaction cost and increase their trades using their social capital.

This review looks at empirical evidence to the existing literature on the role of social capital for in rural Ethiopia. Specifically, what types of social networks are practiced and what are their contributions.

\section{Social capital in rural Ethiopia agrarian society}

Today agricultural sector does not need only the supply of inputs and technologies, rather it requires also considerations of different institutional arrangements existing in agrarian societies. With this view I have tried to review different articles that consider social capital as one main input in Ethiopian agriculture and looked at their different role.

One of the most celebrated social capitals in Ethiopian rural agrarian society is Debo. Debo ${ }^{l}$ is a labor sharing mechanism among Ethiopian farmers. The system allows either neighbors or relatives to share the available labor force for any members of Debo during preparation, plough, seedling, weeding, harvesting or for any kind of farming or livestock rearing activities. It is obvious that it lowers the labor cost that the farmers or the entity would incur for hiring a labor. Hence it reduces the production cost.

Nizam A.,et al (2017) analyzed the effect of being membership of Debo for soil and water conservation practices (SWC) and productivity enhancing technologies(PET) adopters and non-adopters. The paper employed data collected in a socio-economic household survey that is carried out during March to May 2014 among Ethiopian farmers. The sample is limited to 398 households living in a $200 \mathrm{~km}$ radius around Hawassa town. Accordingly, the members of Debo, and adopters and non-adopters of both SWC and PET were nearly $23 \%$.In this regard, the study debates that for adoption Soil and Water Conservation practices, it has typical governance challenge which is a free riding problem. This means, the final results of the common pool resource will be

\footnotetext{
${ }^{1}$ In some part of the country, it is also called webera.
} 
shared among all the participants regardless of their level and frequency of participation. However, argument regarding productivity enhancing technologies is that Debo might have positive effects on adoption since the farmers can control the performance of the Debo members.

In general, through such a system farmers also help those who fall sick during a planting or harvesting season. Sentiments like "sharing experiences in times of joy and sadness" constitute the most important aspect. Though the contribution of Debo could vary among Ethiopian rural society, its immense contribution during labor shortage period and its effective communication ways for members of Debo makes it still to be a longlasting social capital in Ethiopian rural agrarian societies.

Another strongest type of social capital practiced in Ethiopian rural agrarian society is Jarsumma. The Jarsumma is derived from the word "Jaarsa" in Afan Oromo (the language of Oromo people) which means elders. The Jarsumma is the procedure of solving dispute among individuals, groups or tribes on common or private resources or ethnic based conflicts through truth and win-win mechanism (Bayeh, 2015).

Hence for any local farmers, in the view of the community, being a member of Jarsumma is considered as prestige and respect due to the fact the decision passed by such system is almost accepted by those members and the community. Hence, its contribution in local conflict resolution and adopting new agricultural technology practices is huge. For example, in recent period the Ethiopian government have introduced and advised a row planting practice. There was resistance among the farmers in practice, even though not all. In most part of the country, the benefit and the effect of row planting was solved via Jarsumma (though a different kind of name is given to it in different parts of the region).

The other is "Idir and Ikub". Idirl is a social activity for provision of social and economic insurance for the members in the events of death, accident, damages to property, and the like. ; Idir help cover costs incurred during a funeral and other emergency situations, and as such, are insurance organizations. A result it is considered as a means, if for example, the farmer or member of the idir is in the short money due to either crop failure or seasonality of production from which income is generated, it acts as insurance. Hence, belonging to Idir, having some form of relationship with network members in terms of kinship or informal forms of insurance, or having a high frequency of meetings with a network member, all seem to increase the probability of forming an information link. With this premise, they can all also talk the existing practices and/or problems about their daily of agriculture.

"Ikub" is "an economic association by a group of individuals who agree to make regular contributions to a fund which is given, in whole or in part, to each contributor in rotation". The basic principle upon which Ikub is organized is that a fixed amount of money is collected from each participant, and this fund is given to one of the participants in turn. Hence it is considered as a rotating savings and credit association. The person who receives the fund at a particular meeting is determined by drawing a lottery. The drawing of the lottery, however, may not coincide with the credit needs of the members. Accordingly, if one members of Ikub (farmer) is in need of credit, with some monetary reward for the winner and agreement, then the farmer will take this round. As a result Ikub serves as one of the safe and nearby source for financing his/her agricultural activities either in absence or presence of formal credit institutions. Farmers' association (often referred to by its former name, peasant association): This association, based in a rural kebele $^{2}$, is a semi-autonomous entity that is directly involved in decisions regarding the land, water, natural resources and other productive, social and political issues that affect the lives of all community members.

Besides the major ones, there are also other social capital indicators emerging and practiced in rural Ethiopian agrarian society. Among those, agricultural producer's cooperatives, water use group, watershed group, forest use group, business group and women association the major one.

In general, those social capitals, whether they do have a positive or negative effect, they should be modeled or considered as one of the input in agricultural production, since in either or indirect way, their existence is inevitable where the social norms and networks are huge in rural Ethiopia.

\section{Concluding remark}

Social capital is more widely accepted as one asset not only by the academics but people in the business world, its applications and measurement systems have been developed and used with specific objectives on community levels and national levels.

Social capital in agriculture is its role and place when farmers and non-farming people live in the same community. Farmers might attempt to develop social capital or neighborly relations with non-farming neighbors in order to mitigate social constraints created by non-farming concerns within farming communities. Relationships from the non-farming people, when it indicates support and tolerance of agriculture to be high, especially when non-farmers appreciate the existence of social capital with majority of the practicing farmers, it will lead to creating synergy between the two groups and subsequently leading to beneficial relationships for

\footnotetext{
${ }^{1}$ It is called Afosha in Hararge.

${ }^{2}$ It is the smallest administrative unit in Ethiopia.
} 
both the two components of the community, creating develop well-being and cordiality (Sharp and Smith, 2003). In this conception of social capital, the key issue in the community is not social ties per se, but rather the "scaling up" of these ties to form organizations that are economically effective for enhancing agricultural productivity within the various strata of the community.

But in Ethiopian context, its role and significance is almost ignored. Thus, identifying the types and dimensions of the social capital in order to estimate their probable effects is important.

Finally their practicability standards and measurement should be a future research focus with particular emphasis in rural Ethiopian agrarian society.

\section{References}

Bayeh, E., Ayferam, G., \& Muchie, Z. (2015). Traditional Conflict Resolution as a Better Option to Court Proceeding: An Attitude and Practice in Ambo Town, 3(April), 206-208.

Fafchamps, M. (2011). Risk Sharing Between Households. In Handbook of Social Economics, Volume 1A Chapter 24. Elsevier.

Gabre-Madhin, E. G. Market Institutions, Transaction Costs, and Social Capital in the Ethiopian Grain Market, Research Report 124, International Food Policy Research Institute, Washington, D.C. 2001.

Nizam A. Husen, Tim K. Loos, and Khalid H.A. Siddig, "Social Capital and Agricultural Technology Adoption among Ethiopian Farmers." American Journal of Rural Development, vol. 5, no. 3 (2017): 65-72. doi: 10.12691/ajrd-5-3-2.

Jackson, M. O. \& L. Yariv. (2011). Diffusion, Strategic Interaction, and Social Structure. In Handbook of Social Economics, Volume 1A Chapter 14. Elsevier.

Jackson, M. O. (2011). An Overview of Social Networks and Economic Applications. In Handbook of Social Economics, Volume 1A Chapter 12. Elsevier.

Munshi, K., 2004. Social learning in a heterogeneous population: technology diffusion in the Indian Green Revolution. J. Dev. Econ. 73, 185-213. doi:10.1016/j.jdeveco.2003.03.003

Sharp, J. S., \& Smith, M. B. (2003). Social capital and farming at the rural-urban interface: the importance of nonfarmer and farmer relations.Agricultural systems, 76(3), 913-927.

Wong, S. (2007). Exploring 'unseen' social capital in community participation, Amsterdam University Press.

Yesuf, M. and R. A. Bluffstone. (2012). Poverty, Risk Aversion, and Path Dependence in Low-Income Countries: Experimental Evidence from Ethiopia. Amer. J. Agr. Econ. 91(4) 1022-1037 